\title{
Lesão nodular fibrosa em rebordo alveolar em paciente com transtorno do espectro autista
}

Fibrosal nodular injury in alveolar flush in a patient with autistic spectrum disorder Lesión nodular fibrosa en rebordo alveolar en paciente con transtorno del espectro autista

\author{
Francielly Thomas FIGUEIREDO ${ }^{1}$ \\ Aline Bergman de Souza HERCULANO² \\ Diego Silva de CASTRO ${ }^{3}$ \\ Eduardo Ferreira da MOTTA \\ Karla Ferreira Dias SALDANHA ${ }^{5}$ \\ Guilherme Soares da SILVA ${ }^{6}$ \\ Júlio Cesar Leite da SILVA \\ Elerson GAETTI-JARDIM JUNIOR \\ Ellen Cristina GAETTI-JARDIM ${ }^{7}$
}

\begin{abstract}
${ }^{1}$ Aluna de Graduação, Faculdade de Odontologia, Universidade Federal de Mato Grosso do Sul (UFMS) 79070-900 Campo Grande-MS, Brasil ${ }^{2}$ Residente em Cirurgia Bucomaxilofacial, Hospital Universitário Maria Aparecida Pedrossian Universidade Federal de Mato Grosso do Sul (UFMS) 79070-900 Campo Grande-MS, Brasil

${ }^{3}$ Residente em Odontologia, Hospital Universitário Maria Aparecida Pedrossian, Universidade Federal de Mato Grosso do Sul (UFMS) 79070-900 Campo Grande-MS, Brasil

${ }^{4}$ Doutor em Odontologia, Responsável pelo Setor de Odontologia do Hospital São Julião, 79017-200 Campo Grande-MS, Brasil.

${ }^{5}$ Especialista em Pacientes Especiais, Residência em Odontologia, Hospital Universitário Maria Aparecida Pedrossian, Universidade Federal de Mato Grosso do Sul (UFMS) 79070-900 Campo Grande-MS, Brasil

${ }^{6}$ Mestrando em Odontologia, Faculdade de Odontologia, Universidade Federal de Mato Grosso do Sul (UFMS) 79070-900 Campo Grande-MS, Brasil ${ }^{7}$ Prof. Dr. Disciplina de Cirurgia Bucomaxilofacial, Preceptor das Residências em Odontologia e Cirurgia Bucomaxilofacial do Hospital Universitário Maria Aparecida Pedrossian, Universidade Federal de Mato Grosso do Sul (UFMS) 79070-900 Campo Grande-MS, Brasil ${ }^{8}$ Departamento de Patologia e Propedêutica Clínica, Faculdade de Odontologia de Araçatuba, Universidade Estadual Paulista (UNESP), 16015-050 Araçatuba-SP, Brasil
\end{abstract}

\section{Resumo}

O fibroma ossificante periférico é uma patologia comum dos maxilares ocorrendo sobretudo pelo acúmulo de restos alimentares e traumatismos à gengiva e rebordo alveolar. Apresenta-se geralmente como um nódulo de limites definidos e de coloração semelhante a mucosa adjacente sendo normalmente assintomático, a depender do tamanho do mesmo. O objetivo deste artigo é apresentar um caso de paciente com 49 anos de idade com espectro autista, de comportamento difícil e nenhuma possibilidade de inter-relacionar-se com o cirurgião-dentista, com necessidade de exodontias múltiplas e remoção de fibroma ossificante periférico, em região de maxila a direita, de amplo tamanho. O paciente foi submetido aos procedimentos cirúrgicos em centro cirúrgico sob anestesia geral. Após remoção dos focos dentários e da lesão exofítica o paciente não apresentou recidiva da mesma.

Descritores: Fibroma Ossificante; Diagnóstico; Terapêutica.

\section{Abstract}

Peripheral ossifying fibroma is a common pathology of the jaws occurring mainly by the accumulation of food remains and trauma to the gingiva and alveolar ridge. It is generally present as a nodule of defined borders and of coloration similar to the adjacent mucosa being normally asymptomatic, depending on its size. The objective of this article is to present a case of a 49-year-old patient with autistic spectrum of difficult behavior and no possibility of interrelating with the dentist, requiring multiple exodontia and removal of peripheral ossifying fibroma in region of maxilla to the right, of ample size. The patient underwent surgical procedures in a surgical center under general anesthesia. After removal of the dental foci and exophytic lesion, the patient did not present recurrence.

Descriptors: Fibroma, Ossifiyng; Diagnosis; Therapeutics.

\section{Resumen}

El fibroma osificante periférico es una patología común de los maxilares ocurriendo sobre todo por la acumulación de restos alimentarios Y traumatismos a la encía Y el borde alveolar. Se presenta generalmente como un nódulo de límites definidos y de coloración similar a la mucosa adyacente siendo normalmente asintomático, dependiendo del tamaño del mismo. El objetivo de este artículo es presentar un caso de paciente con 49 años de edad con espectro autista, de comportamiento difícil Y ninguna posibilidad de interrelacionarse con el cirujanodentista, con necesidad de exodontias múltiples Y remoción de fibroma osificante periférico, en región de mandíbula a la derecha, de amplio tamaño. El paciente fue sometido a los procedimientos quirúrgicos en un centro quirúrgico bajo anestesia general. Después de la remoción de los focos dentales Y de la lesión exofítica el paciente no presentó recidiva de la misma.

Descriptores: Fibroma Osificante; Diagnóstico; Terapéutica.

\section{INTRODUÇÃO}

O fibroma ossificante periférico (FOP) é uma lesão reacional benigna dos maxilares de etiologia múltipla, desde a presença de cálculo dentários e placa bacteriana, bem como traumatismo pelo aparelho ortodôntico ou restaurações, dentes fraturados e impactação de alimentos ${ }^{1}$.

Possui predileção pela gengiva vestibular de mandíbula ${ }^{2}$, mas pode ocorrer em qualquer ponto da superfície mucosa, com predileção do sexo feminino, região posterior de maxila e segunda década de vida ${ }^{3}$.

Clinicamente se apresenta como massa exofítica de coloração semelhante à mucosa adjacente a mesma, podendo mostrar pontos de ulceração, dependendo da extensão do FOP, sendo resultado de mordeduras sobre a mesma. Apresenta cerca de $2 \mathrm{~cm}$ em sua maior extensão ${ }^{3}$ e raramente provoca deslocamento dental, sendo mais comum o apinhamento dental ser o responsável pelo surgimento da patologia uma vez que favorece o acúmulo de restos alimentares e placa bacteriana.

O tratamento de escolha para o FOP é a exérese total e a remoção do fator causal com prognóstico favorável e ausência de recidiva quando da eliminação total dos possíveis fatores causais ${ }^{4}$.

No tocante ao atendimento ao paciente com espectro autista, como definido por Mugayar ${ }^{5}$ : 
pacientes com necessidades especiais são todos aqueles que apresentam alteração dos níveis de normalidade, por uma doença ou alteração clínica, que necessita para tanto abordagens odontológica diferenciadas.

Deste modo, em virtude de tal definição, o atendimento odontológico ao paciente com espectro autista é marcado por inúmeros desafios. O atendimento em nível ambulatorial ou de consultório em virtude das dificuldades de interação dos autistas pelo seu difícil comportamento fazem com que o cirurgião-dentista tenha dificuldade em atendê-los sob anestesia local tendo deste modo a anestesia geral a grande vantagem de realização dos procedimentos em única sessão ${ }^{6}$.

Sendo assim, o objetivo do trabalho apresentar um caso de paciente com espectro autista com extensa lesão reacional em rebordo maxilar a direita tratado cirurgicamente em centro cirúrgico sob anestesia geral.

\section{CASO CLÍNICO}

Paciente do gênero masculino, 49 anos de idade, com diagnóstico de Transtorno do Espectro Autista, compareceu ao ambulatório odontológico, acompanhado pela mãe, que relatou agitação extrema do filho em atendimentos convencionais anteriores, levando ao insucesso de várias tentativas de procedimentos odontológicos.

$\mathrm{Na}$ anamnese, a acompanhante relatou histórico de crises convulsivas, sendo o último episódio há alguns anos, fazendo uso de medicações contínuas como Tegretol e Carbamazepina, além de histórico de alergia a corantes e refrigerante, e dificuldade de realizar corretamente a higiene oral do paciente, devido a não colaboração do mesmo. Ao exame clínico pode-se observar múltiplas raízes residuais e uma lesão nodular de aproximadamente $2,5 \mathrm{~cm}$ em rebordo alveolar superior direito e de coloração semelhante à mucosa oral (Figuras 1 a 3). $\mathrm{O}$ atendimento odontológico sob anestesia geral foi a opção dos profissionais, de tal forma a viabilizar o tratamento de um paciente não colaborativo ao atendimento em ambulatório.

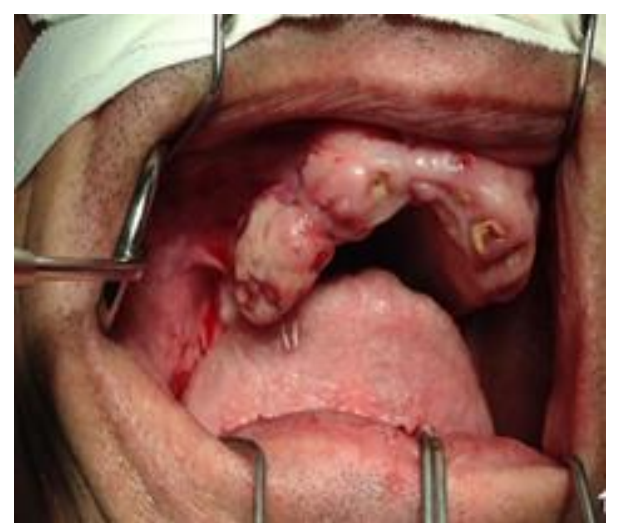

Figura 1: Vista clínica inicial. Higiene bucal deficiente e presença de aumento volumétrico em gengiva maxilar a direita.

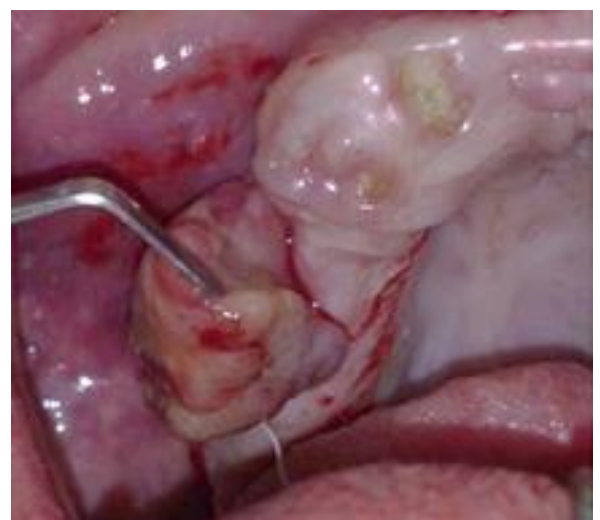

Figura 2: Aumento volumétrico em rebordo maxilar direito de cerca de $2,5 \mathrm{~cm}$.

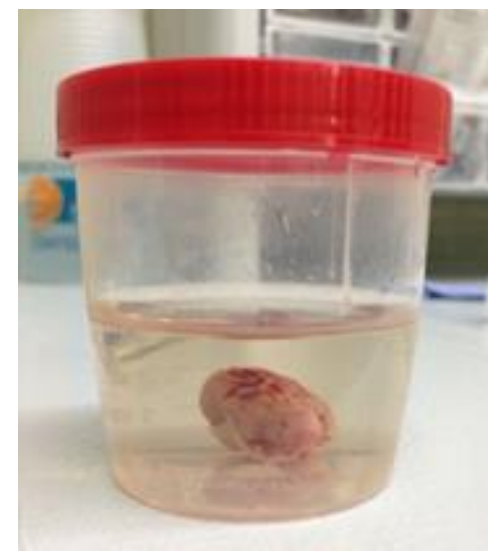

Figura 3: Acondicionamento da peça cirúrgica para envio a análise histopatológica.

Após avaliação médica, o risco cirúrgico foi Goldman 1, sendo o paciente levado para atendimento em centro cirúrgico, sendo realizado exodontia de todas as raízes residuais e exérese total da lesão exofítica. A amostra foi acondicionada em recipiente com formol a $10 \%$ e levada para análise histopatológica.

Após 15 dias dos procedimentos o laudo histopatológico mostrou se tratar de proliferação fusocelular mesenquimal vascularizada, com ulceração, presença de células gigantes multinucleares permeadas a trabéculas ósseas de padrão reacional e formação de tecido de granulação, com ausência de necrose. A atipia celular moderada juntamente às demais características histopatológicas, sugeriu o diagnóstico de fibroma ossificante periférico. Após a remoção da patologia não houve recidiva da mesma.

\section{DISCUSSÃO}

$\mathrm{O}$ atendimento odontológico ao paciente com necessidades especiais, como o paciente autista, é um grande desafio ao cirurgião-dentista. $\mathrm{O}$ atendimento ao paciente em questão sob anestesia geral foi fundamental para a resolução do quadro já que a presença de inúmeros focos infecciosos coadjuvados pela lesão exofítica demandariam inúmeras sessões ambulatoriais para o tratamento além do grande desgaste a que o paciente seria submetido. 
O tratamento de eleição para fibroma ossificante periférico é a ressecção cirúrgica envolvendo o ligamento periodontal e o periósteo ${ }^{4,7}$ com eliminação dos possíveis focos de irritação local como a placa bacteriana, fato este comprovado pela apresentação do caso clinico uma vez que o paciente possuía em virtude da dificuldade de higienização, problema periodontal e cáries em todos os elementos dentários. A remoção dos focos infecciosos foi fundamental para a resolução do caso uma vez que remove o fator etiológico e reduz sobremaneira a possibilidade de recidiva da lesão ${ }^{8}$.

Em virtude do fibroma ossificante periférica se enquadrar como uma patologia reacional a terapêutica aqui empregada foi satisfatória para a resolução do caso e em pós-operatório não foi observada qualquer foco de recidiva. Além disso, associado às inúmeras necessidades odontológicas, $\mathrm{o}$ fato do paciente não ser colaborativo indicou a necessidade de anestesia geral já que a dificuldade de comunicação e colaboração impediria a realização do procedimento ambulatorial ${ }^{9}$.

\section{CONCLUSÃO}

Em virtude da complexidade do paciente, o procedimento sob anestesia geral foi fundamental para a remoção da patologia e devolver qualidade de vida, permitindo a eliminação de focos infecciosos bucais em apenas um procedimento cirúrgico.

\section{REFERÊNCIAS}

1. Feller L, Buskin A, Raubenheimer EJ. Cementoossifying fibroma: case report and review of the literature. J Int Acad Periodontol. 2004; 6(4):131-35.

2. Mishra MB, Bhishen KA, Mishra S. Peripheral ossifying fibroma. J Oral Maxillofac Pathol. 2011;15(1):65-8.

3. García de Marcos JA, García de Marcos MJ, Arroyo Rodríguez S, Chiarri Rodrigo J, Poblet E. Peripheral ossifying fibroma: a clinical and immunohistochemical study of four cases. J Oral Sci. 2010;52(1):95-9.

4. Kumar SK, Ram S, Jorgensen MG, Shuler CF, Sedghizadeh PP. Multicentric peripheral ossifying fibroma. J Oral Sci. 2006;48(4):239-43.

5. Mugayar LRF. Pacientes portadores de necessidades especiais. Manual de Odontologia e Saúde Oral. Pancast: São Paulo; 2000.

6. Andrade APP, Eleutéio ASL. Pacientes portadores de necessidades especiais: abordagem odontológica e anestesia geral. Rev bras odontol. 2015;72(1/2):66-9.

7. Neville BW, Damm DD, Allen CM, Bouquot JE. Patologia Oral \& Maxilofacial. 2 ed. Rio de Janeiro: Guanabara Koogan; 2004.
8. Sabino NAR, Gaetti-Jardim EC, Gaetti-Jardim Jr E, de Melo RL. Arch Health Invest. 2016;5(4):214-16.

9. Haddad AS. Odontologia para pacientes com necessidades especiais. São Paulo: Santos; 2007.

\section{CONFLITO DE INTERESSES}

Os autores declaram não haver conflitos de interesse.

\section{AUTOR PARA CORRESPONDENCIA}

\section{Ellen Cristina Gaetti Jardim}

ellen.jardim@ufms.br 